\title{
Clinical picture of patients with Barrett's esophagus and different grades of dysplasia
}

\begin{abstract}
Introduction: Barrett's esophagus (BE) is the most relevant premalignant condition for the development of carcinoma of the esophagus, and the presence of dysplasia represents a progression marker.
\end{abstract}

Objectives: To identify the different clinical manifestations in a group of patients with $\mathrm{BE}$ and different grades of dysplasia.

Methods: An observational, descriptive and transversal study was carried out which included 86 patients with a diagnosis of BE seen at the Endoscopy Department from the National Center for Minimally Invasive Surgery between January 2012 and January 2014. Clinical-epidemiological variables were compared according to the presence or not of dysplasia and its grade.

Results: 52 male patients were included (60,5\%BMI95\%:49,5-71,3) and 34

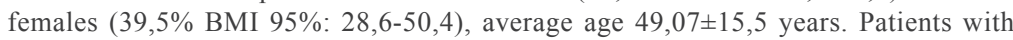
white skin prevailed, 77 (89,5\% BMI 95\%: 82,4-96,5). 49 cases had no dysplasia (57\%,BMI95\%:45,93-68,02); high-grade dysplasia was found in five cases $(5,8 \%$ BMI 95\%:1,91-13,04) and low-grade dysplasia in 32(37,2\% BMI95\%:26,41-48,006). Dysplasia was found in younger individuals, with $45,5 \pm 16,5$ years (BMI 95\%: 39,5$51,4)$ and $41,6(20,5)$ years (BMI95\%:16,1-67) as average age for those with low and high-grade dysplasia, respectively. The progression of symptoms in patients with lowgrade dysplasia was longer $(8,7 \pm 7,9$ years). The body mass index (BMI) was higher in the group without dysplasia $(26,4 \pm 4,3)$.

Conclusion: There are differences regarding age and progression of typical symptoms in patients with dysplasia. Nevertheless, the rest of the assessed conditions were not always present; that is the reason it was not demonstrated that they were more intense in these patients.

Keywords: barrett's esophagus, dysplasia, clinical picture, endoscopy
Volume 9 Issue 3 - 2018

\author{
Vivianne Anido Escobar,' Mirtha Infante \\ Velázquez ${ }^{2}$ \\ 'Doctor in Medicine, Specialist in Gastroenterology, National \\ Center for Minimally Invasive Surgery, Cuba \\ ${ }^{2}$ Doctor in Medicine, Specialist in Gastroenterology, Nationa \\ Institute of Gastroenterology, Cuba
}

Correspondence: Vivianne Anido Escobar, Doctor in Medicine, Specialist in Gastroenterology, National Center for Minimally Invasive Surgery, La Habana, Cuba,

Email vivianne.anido08@gmail.com, vivianne@cce.sld.cu

Received: January 23, 2018 | Published: May 09, 2018

\section{Introduction}

Barrett's esophagus (BE) is a chronic consequence due to gastroesophageal reflux disease (GERD), the most prevalent gastrointestinal disorder worldwide. It is estimated that approximately $10 \%$ of the adult population can experience GERD symptoms such as pyrosis and regurgitation. Moreover, between $10 \%$ and $12 \%$ of the patients that undergo endoscopy due to GERD can have BE. The histologic changes that characterize $\mathrm{BE}$ arise as a direct result of the damage that the pathological reflux of the gastric content generates on the esophageal mucosa, affecting the mechanisms that make its re-epithelization possible. This is determined by the presence of certain genetic characteristics, which associated to external factors, stimulate the differentiation of pluripotential stem cells towards an altered proliferation phenotype, in this case intestinal metaplasia. It is considered as a precursor lesion of esophageal adenocarcinoma. ${ }^{1,2}$ Up to the present, dysplasia is the most useful clinical biomarker that allows us to suspect BE malignant potential. The possible differences that can exist in the clinical manifestations of a group of patients with $\mathrm{BE}$ and different grades of dysplasia are studied in this article.

\section{Material and method}

An observational, descriptive and transversal study was carried out which included 86 patients with a diagnosis of $\mathrm{BE}$ seen at the
Endoscopy Department of the National Center for Minimally Invasive Surgery between January 2012 and January 2014. The patients had a previous positive diagnosis for $\mathrm{BE}$ or an endoscopic picture suspicious of intestinal metaplasia when the endoscopy was performed due to digestive symptoms. This refers to the presence of salmon-red colored mucosa above the gastroesophageal junction.

All the patients were interviewed in a specific doctor's office. A form for data collection in which demographic and clinical evaluation was initially registered was completed. An Olympus Evis Lucera Spectrum FQ-260 video endoscope was used for endoscopy. Samples for pathologic study were taken following Seattle protocol (biopsy from the 4 quadrants, each sample at $2 \mathrm{~cm}$ interval), that confirmed $\mathrm{BE}$ diagnosis. The biopsies were examined by two experienced pathologists. The existence or not of dysplasia was determined and classified as high-grade or low-grade dysplasia and undetermined. ${ }^{3}$

The symptoms were considered as esophageal syndrome and extra esophageal syndrome following Montreal classification. ${ }^{4}$ Patients with previous history of pyrosis, acid regurgitations and esophageal damage due to previously known gastroesophageal reflux (esophagitis, stenosis, BE) were defined as esophageal syndrome carriers. Extra esophageal syndrome was established for those cases that had manifestations with well-established associations to GERD such as: chronic cough, chronic laryngitis, bronchial asthma and 
dental erosions. There are other associations with GERD but they were not considered because of their poor correlation or wide variety of causes. ${ }^{5}$ The body mass index (BMI) was determined by dividing body weight $(\mathrm{Kg})$ by height $\left(\mathrm{m}^{2}\right)$ and classified according to the World Health Organization criteria as: malnourished/underweight $(<18.5 \mathrm{~kg}$ / $\left.\mathrm{m}^{2}\right)$, normal weight $\left(18.5-24.9 \mathrm{~kg} / \mathrm{m}^{2}\right)$, overweight $\left(25-29.9 \mathrm{~kg} / \mathrm{m}^{2}\right)$ and obese $\left(\geq 30 \mathrm{~kg} / \mathrm{m}^{2}\right){ }^{6}$

Statistical data analysis was done using the SPSS system, version number 21. Variables were organized in contingency tables according to the different type groups of dysplasia. The groups were compared through Chi-Square test or Fisher's exact test (whenever the expected frequencies were under 5) for the qualitative variables and the unidirectional variance analysis (test F) or the Kruskal-Wallis test with the quantitative variables, depending on if they followed a normal distribution or not. In every case the statistical significance level was 0,05 . All the patients gave their written consent to participate in the investigation, undergo the endoscopic examination and biopsy. The protocol was approved by the Institutional Review Board.

\section{Results}

A total of 86 patients were included in the study, 52 males $(60,5 \%$ BMI 95\%:49,5-71,3) and 34 females (39,5\% BMI 95\%:28,6-50,4), with an average age of $49.07 \pm 15,5$ years. According to skin color, $77(89,5 \%$ BMI 95\%:82,4-96,5) are white; six black (7\% BMI 95\%:1,01-12,9) and three patients of mixed race (3,5\% BMI 95\%:0,7$9,8)$. Over half of the patients $(49 / 86)$ had no dysplasia $(57 \%$, BMI 95\%:45,93-68,02); dysplasia was found in 37 cases (43\%, BMI 95\%: 31,97-54,06). It was classified as high-grade dysplasia in five cases $(5,8 \%$ BMI 95\%:1,91-13,04), and as low-grade dysplasia in 32 patients (37,2\% BMI 95\%:26,41-48,006); undetermined dysplasia was not found. Dysplasia was seen in younger patients. Average age was $52,1(13,9)$ years (BMI 95\%:48,1-56,1) in the group with no dysplasia, and 45,5(16,5) years (BMI 95\%:39,5-51,4) and 41,6(20,5) years (BMI 95\%:16,1-67) for low and high-grade dysplasia, respectively. Comparison among differences had no statistical significance $(\mathrm{F}=2,43 ; \mathrm{p}=0,09)$

Male patients prevailed, both in cases with or without dysplasia. The proportion of cases with dysplasia was lower among women. Three of them (3,5\% BMI 95\%:0,7-9,8) had low-grade dysplasia and 10(11,6\%; BMI 95\%: 4,2-18,9) high-grade dysplasia. There was no significant statistical difference. $\left(\mathrm{X}^{2}=0,09 ; \mathrm{p}=0,36\right)$. The presence of patients with white skin was also higher in those without dysplasia $(51,1 \%$ IC $95 \%$ : 40,01-62,30), as in those with high $(33,7 \% \mathrm{IC} 95 \%: 23,14-44,29)$ and low-grade dysplasia $(4,6 \%$ IC $95 \%: 1,28-11,48)$, although without significant differences $\left(X^{2}=4,74\right.$; $\mathrm{p}=0,31)$. Overweight or obese patients prevailed among those without dysplasia, as in those with high or low-grade dysplasia, without significant differences $\left(\mathrm{X}^{2}=11,6 ; \mathrm{p}=0,07\right)$. This information is presented in Table 1. The arithmetic mean of the body mass index was higher in the group without dysplasia $26,4(4,3)$, compared to those with low $25,7(3,6)$ and high-grade dysplasia $24,4(5,2)$. Comparison did not show significant differences $(\mathrm{F}=0,69 ; \mathrm{p}=0,50)$.

A higher frequency of patients that presented the symptoms that typify esophageal syndrome was observed $(73 / 86 ; 84,8 \%$ BMI 95\%:76,7-93). It was higher in the group without dysplasia (40/89;46,5\% BMI 95\%:35,3-57,6), compared to the low-grade (29/86; 33,7\% BMI 95\%:23,1-44,2) and high-grade dysplasia groups (4/86;4,6\% BMI 95\%:1,2-11,4). Differences did not have statistical significance $\left(\mathrm{X}^{2}=1,31 ; \mathrm{p}=0,51\right)$. This information is summarized in Table 2. The progression of symptoms in the group of patients with low-grade dysplasia was longer $(8,7 \pm 7,9$ años) with regard to those with no dysplasia $(5,4 \pm 3,1$ años) or it was shorter $(5,8 \pm 5,4$ años). Comparison among the groups showed no statistical significant differences $(\mathrm{p}=0.27)$.

Table I Comparison of demographic and clinical variables according to grades of dysplasia

\begin{tabular}{|c|c|c|c|c|c|}
\hline Variables & & No dysplasia & Low-grade dysplasia & High-grade dysplasia & Total \\
\hline \multicolumn{6}{|l|}{ Sex } \\
\hline \multirow[t]{3}{*}{ male } & $\mathrm{n}$ & 28 & 22 & 2 & 52 \\
\hline & $\%$ & 32,5 & 25,5 & 2,3 & 60,5 \\
\hline & BMI 95\% & $22-43$ & $15,7-35,3$ & $0,2-8,1$ & $49,5-7 I, 3$ \\
\hline \multirow[t]{3}{*}{ female } & $\mathrm{n}$ & 21 & 10 & 3 & 34 \\
\hline & $\%$ & 24,4 & 11,6 & 3,5 & 39,5 \\
\hline & BMI $95 \%$ & $14,7-34,08$ & $4,2-18,9$ & $0,7-9,8$ & $28,6-50,4$ \\
\hline \multicolumn{6}{|l|}{ Color of the skin } \\
\hline \multirow[t]{3}{*}{ white } & $\mathrm{n}$ & 44 & 29 & 4 & 77 \\
\hline & $\%$ & $5 I, I$ & 33,7 & 4,6 & 89,5 \\
\hline & BMI $95 \%$ & $40,01-62,3$ & $23,1-4,2$ & $|, 2-| \mid, 4$ & $82,4-96,5$ \\
\hline \multirow[t]{3}{*}{ mixed race } & $\mathrm{n}$ & I & I & 1 & 3 \\
\hline & $\%$ & $\mathrm{I}, \mathrm{I}$ & $\mathrm{I}, \mathrm{I}$ & $\mathrm{I}, \mathrm{I}$ & 3,5 \\
\hline & BMI $95 \%$ & $0,02-6,3$ & $0,02-6,3$ & $0,02-6,3$ & $0,7-9,8$ \\
\hline \multirow[t]{3}{*}{ black } & $\mathrm{n}$ & 4 & 2 & 0 & 6 \\
\hline & $\%$ & 4,6 & 2,3 & 0 & 7 \\
\hline & BMI 95\% & $\mathrm{I}, 2-\mathrm{II}, 4$ & $0,2-8,1$ & 0 & $1,01-12,9$ \\
\hline \multicolumn{6}{|l|}{ Nutritional status } \\
\hline \multirow[t]{3}{*}{ underweight/malnourished } & $\mathrm{n}$ & 3 & I & 2 & 6 \\
\hline & $\%$ & 3,5 & $\mathrm{I}, \mathrm{I}$ & 2,3 & 7 \\
\hline & BMI $95 \%$ & $0,7-9,8$ & $0,02-6,3$ & $0,2-8, I$ & $1,01-12,9$ \\
\hline normal weight & $\mathrm{n}$ & 15 & 12 & 0 & 27 \\
\hline
\end{tabular}


Table Continued

\begin{tabular}{|c|c|c|c|c|c|}
\hline \multirow[t]{2}{*}{ Variables } & & No dysplasia & Low-grade dysplasia & High-grade dysplasia & Total \\
\hline & $\%$ & 17,4 & 13,9 & 0 & 31,3 \\
\hline & BMI $95 \%$ & $8,8-26,04$ & $6,04-21,8$ & 0 & $2 \mathrm{I}-4 \mathrm{I}, 7$ \\
\hline \multirow[t]{3}{*}{ overweight } & $\mathrm{n}$ & 24 & 16 & 3 & 40 \\
\hline & $\%$ & 27,9 & 18,6 & 3,5 & 46,5 \\
\hline & BMI $95 \%$ & $17,8-37,9$ & $9,7-27,4$ & $0,7-9,8$ & $35,3-57,6$ \\
\hline \multirow[t]{3}{*}{ obese } & $\mathrm{n}$ & 7 & 3 & 0 & 10 \\
\hline & $\%$ & 3,5 & 3,5 & 0 & 11,6 \\
\hline & BMI 95\% & $0,7-9,8$ & $0,7-9,8$ & 0 & $4,2-18,9$ \\
\hline \multicolumn{2}{|l|}{ Clinical symptoms } & No dysplasia & Low-grade dysplasia & High-grade dysplasia & Total \\
\hline \multirow[t]{3}{*}{ Esophageal syndrome } & $\mathrm{n}$ & 40 & 29 & 4 & 73 \\
\hline & $\%$ & 46,5 & 33,7 & 4,6 & 84,8 \\
\hline & BMI 95\% & $35,3-57,6$ & $23, I-44,2$ & $|, 2-| I, 4$ & $76,7-93$ \\
\hline \multirow{3}{*}{$\begin{array}{l}\text { Extra esophageal } \\
\text { syndrome }\end{array}$} & $n$ & 9 & 3 & I & 13 \\
\hline & $\%$ & 10,4 & 3,4 & $\mathrm{I}, \mathrm{I}$ & 15,1 \\
\hline & BMI $95 \%$ & $3,4-17,5$ & $0,7-9,8$ & $0,02-6,3$ & $6,9-23,2$ \\
\hline Total & $\mathrm{n}$ & 49 & 32 & 5 & 86 \\
\hline & $\%$ & 56,9 & 37,2 & 5,8 & 100 \\
\hline & BMI $95 \%$ & $45,9-68$ & $26,4-48$ & $1,9-13$ & \\
\hline
\end{tabular}

\section{Discussion}

Identification of possible differences regarding clinical and epidemiological variables according to the existence or not of dysplasia and its grade, can offer information to support adequate use of esophageal cancer screening and surveillance programs. It can also determine which could be the population at higher risk that would be benefitted by using these strategies, adjusted to the possibilities of the Cuban health care system. Regarding BE, this series showed the expected clinical-epidemiological manifestations: males and white race prevailed, and an average age close to 50 years. It is in keeping with the results of the studies reviewed on the topic that consider these elements as relevant, not modifiable risk factors, which are included in screening and surveillance programs. ${ }^{7,8}$

Despite prevailing BE cases with no dysplasia, a not inconsiderable number of cases with dysplasia were diagnosed. This allows us to consider that the biopsy samples were well oriented, as well as suspect that there could be a higher prevalence of dysplasia in BE patients and support the relevance of diagnostic and follow-up programs with these cases. Dysplasia was found in younger individuals, and above all, high-grade dysplasia. This observation can be explained by those genetic theories that predispose to this suffering and that do not necessarily require long exposure to environmental factors, not yet well involved. ${ }^{9-11}$

As to nutritional status, what was observed is in keeping with what was stated by Thrift et al. ${ }^{12}$ in a study in which they used bioimpedance. They showed that the increase in body fat or the BMI did not raise the risk for BE, but was related with central adiposity. In a meta-analysis study it was found that patients with metabolic syndrome are at risk for developing BE. ${ }^{13}$

The data about the presence and duration of symptoms provided by the scientific literature reviewed are currently a subject under discussion and give rise to contrasting opinions. ${ }^{10,14}$ The prevalence of typical symptoms, indifferent regarding the grade of the lesion, allow us to doubt the interpretation of former studies which suggest that there is less esophageal sensitivity in BE patients, due to modifications caused by the alterations of the new modified and damaged mucosa. ${ }^{10}$ Anandasabapathy ${ }^{7}$ and Sierra ${ }^{15}$ have found a great number of falsenegatives and false-positives in their studies. It is our criterion that the existence of modified mucosa areas, mostly small surfaces, do not achieve to diminish esophageal sensitivity, globally.

The prevalence of typical symptoms of the disease in patients with dysplasia is related to the existence of repeated mucosal damage caused by acid-peptic secretions (with or without biliary-pancreatic content), which is necessary so as to have a repairing and proliferative response that induces the appearance of metaplasia and later, dysplasia. In these cases the symptoms progressed for a longer time, the same as other authors have reported. ${ }^{10,16}$

Meyer et al were the first to establish the role of BE biliary reflux in humans in $1979 .{ }^{17}$ Since then and up to now most papers about the subject agree that the physiopathological elements in the disease are combined acid and biliary reflux. In the cases with high-grade dysplasia, where this expression did not take place, progression can be influenced more by epigenetic factors than by repeated exposure to digestive juices and environmental factors. ${ }^{18}$

From a meta-analysis of biomarkers predicting risk of malignant progression in Barrett esophagus, by Altaff et al, markers of genomic instability, as loss and mutation of p53, overexpression of Ki-67 and presence of aneuploidy, were reasonably efficient in predicting a higher risk of progressing to HGD and cancer. ${ }^{19}$ Recently, Dong et al. ${ }^{20}$ developed a model to determine risk of Barrett's esophagus or esophageal adenocarcinoma, based on genetic and non-genetic factors even still is not clear if it will justify its clinical use. ${ }^{20}$

New evidences are added day-by-day to support the role of smoking cigarettes and the mean length of BE, like known risk factors in the progression of the HGD to cancer but in the present study, these variables were not aims of study. ${ }^{21,22}$ Surveillance to populations with 
these risk factors have been widely discussed and the situation is more complicate because HGD can be present in patients with non-Barrett's esophagus, but peptic esophagitis, eosinophilic esophagitis and asymptomatic adult and they would have the same risk to progress to cancer. ${ }^{23}$

\section{Conclusion}

We can state that there are certain differences regarding a younger age and longer progression of typical symptoms in patients with dysplasia. The rest of the assessed variables were not always present in the patients with high-grade dysplasia which is the reason why a higher intensity in these cases was not demonstrated. Nevertheless, these observations must be considered carefully given the implications that can arise from working with a low number of patients. The results of this study will lead authors to continue studying the relation among $\mathrm{EB}$, central obesity and metabolic syndrome.

\section{Acknowledgements}

None.

\section{Conflict of interest}

The author declares no conflict of interest.

\section{References}

1. Slehria S, Sharma P. Barrett esophagus. Curr Opin Gastroenterol. 2003;19(4):387-393.

2. Spechler SJ. Barrett esophagus and risk of esophageal cancer: a clinical review. JAMA. 2013;310(6):627-636.

3. Odze RD. Barrett esophagus: histology and pathology for the clinician. Nat Rev Gastroenterol Hepatol. 2009;6(8):478-490.

4. Vakil N, van Zanten SV, Kahrilas P, et al. The Montreal definition and classification of gastroesophageal reflux disease: a global evidencebased consensus. Am J Gastroenterol. 2006;101(8):1900-1920.

5. Chang JY, Talley NJ, Locke GR, et al. Population screening for Barrett esophagus: a prospective randomized pilot study. Mayo Clin Proc. 2011;86(12):1174-1180.

6. Veugelers PJ, Porter GA, Guernsey DL, et al. Obesity and lifestyle risk factors for gastroesophageal reflux disease, Barrett esophagus and esophageal adenocarcinoma. Dis Esophagus. 2006;19(5):321-328.

7. Anandasabapathy S, Jhamb J, Davila M, et al. Clinical and endoscopic factors predict higher pathologic grades of Barrett dysplasia. Cancer. 2007;109(4):668-674.

8. Lippmann QK, Crockett SD, Dellon ES, et al. Quality of life in GERD and Barrett's esophagus is related to gender and manifestation of disease. Am J Gastroenterol. 2009;104(11):2695-2703.

9. Punia RS, Arya S, Mohan H, et al. Spectrum of clinico-pathological changes in Barrett oesophagus. J Assoc Physicians India. 2006;54:187-
10. Freitas M ML, Coelho LGV. Prevalence of Barrett's esophagus in individuals without typical symptoms of gastroesophageal reflux disease. Arq Gastroenterologia. 2008;45(1):46-49.

11. Vergouwe FW, Wijnen RM, Bruno MJ, et al. Prevalence of barrett esophagus in adolescents and young adults with esophageal Atresia. Ann surg. 2016;264(6):1004-1008.

12. Thrift AP, Kramer JR, Alsarraj A, et al. Fat mass by bioelectrical impedance analysis is not associated with increased risk of Barrett esophagus. J Clin Gastroenterol. 2014;48(3):218-223.

13. He Q, Li JD, Huang W, et al. Metabolic syndrome is associated with increased risk of Barrett esophagus: A meta-analysis. Medicine. 2016;95(31):e4338.

14. Bayrakci B, Kasap E, Kitapcioglu G, et al. Low prevalence of erosive esophagitis and Barrett esophagus in a tertiary referral center in Turkey. Turk J Gastroenterol. 2008;19(3):145-151.

15. Sierra F. Incidencia de adenocarcinoma en esófago de Barrett Fundación Santa Fe de Bogotá, 11 años de seguimiento. Rev Col Gastroenterol. 2008;23:1.

16. Sarela AI, Hick DG, Verbeke CS, et al. Persistent acid and bile reflux in asymptomatic patients with Barrett esophagus receiving proton pump inhibitor therapy. Arch Surg. 2004;139(5):547-551.

17. Meyer W, Vollmar F, Bar W. Barrett-esophagus following total gastrectomy. A contribution to it's pathogenesis. Endoscopy. 1979;11(2):121-6.

18. Quante M, Abrams JA, Lee Y, et al. Barrett esophagus: what a mouse model can teach us about human disease. Cell Cycle. 2012;11(23):4328-4338.

19. Altaf K, J-J Xiong, De la Iglesia D, et al. Meta-analysus of biomarkers predicting risk of malignant progression in Barrett's oesophagus. $\mathrm{Br} J$ Surg. 2017;104(5):493-502.

20. Dong J, Buas M, Gharahkhani P, et al. Determining risk of Barrett's esophagus and esophageal adenocarcinoma based on epidemiologic factors and genetic variants. Gastroenterology. 2018,154(5):12731281 .

21. Parasa S, Vennalaganti S, Gaddam S, et al. Development and validation of a model to determine risk of progression of Barrett's esophagus to neoplasia. Gastroenterology. 2018,154(5):1282-1289.

22. Giroux V, Rustqi AK. Metaplasia: tissue injury adaptation and a precursor to the dysplasia-cancer sequence. Nat Rev Cancer. 2017;17(10):594-604.

23. Mwachiro MM, Burgert SL, Lando J, et al. Esophageal squamous dysplasia is common in asymptomatic kenyas: a prospective, community-based, cross-sectional study. Am $J$ Gastroenterol. 2016;111(4):500-507. 